\title{
Knowledge management and communication in Brazilian agricultural research: An integrated procedural approach
}

\author{
Tércia Zavaglia Torres ${ }^{a}$, Ivo Pierozzi Jr. ${ }^{a}$, Nadir Rodrigues Pereira ${ }^{b}$, Alexandre de Castro ${ }^{c, *}$

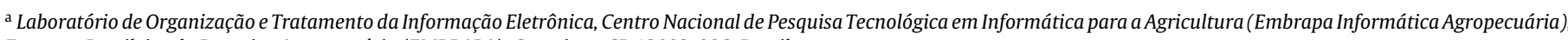 \\ Empresa Brasileira de Pesquisa Agropecuária (EMBRAPA), Campinas, SP 13083-886, Brazil

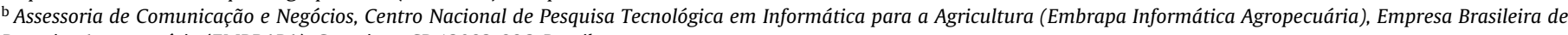 \\ Pesquisa Agropecuária (EMBRAPA), Campinas, SP 13083-886, Brazil

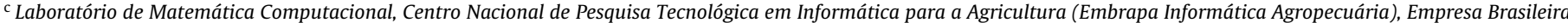 \\ de Pesquisa Agropecuária (EMBRAPA), Campinas, SP 13083-886, Brazil
}

\section{A R T I C L E I N F O}

\section{Keywords:}

Knowledge management

Research networks

Business communication

Organizational learning

RD\&I institution management

\begin{abstract}
A B S T R A C T
The great contemporary organizational challenge for enterprises is to create a conceptual and methodological framework allows the management of knowledge by means of networks designed for social interaction. This statement is based on the premise that the competitive drive and sustainable success of the company depend on the introduction of new forms of production innovative processes, which can only be ensured through integrated approaches to knowledge management and the incorporation information technologies (IT). This is a reality that has already been accepted by the Brazilian Agricultural Research Corporation (Embrapa, its acronym in Portuguese), a Brazilian research, development, and innovation (RD\&I) institution supporting agricultural sector. For some years now, Embrapa has been incorporating what it has learned about knowledge management into its strategic planning process. In this paper, we present a new approach to managing knowledge and information, and we analyze the need for research institutions to administer the knowledge they produce through an RD\&I management model based multi- and inter-disciplinary teams, and multi-institutional research networks.
\end{abstract}

(c) 2010 Elsevier Ltd. All rights reserved.

\section{Introduction}

Since the beginning of the evolution of man, knowledge has been a driving force in the achievements of civilization. The development of knowledge now takes place largely in the organizational space, where its advancement and the incorporation of technologies are responsible for the introduction of new forms of production and of work organization. This new model has changed the industrial dynamic in the developed world and highlighted the central importance of innovative processes, which have become dependent on technological, organizational, and institutional evolution.

Moreover, the major economic, social, environmental, political, and cultural phenomena permeate all dimensions of human life, including the corporate world. Organizations, guided by new management paradigms, are attempting to survive in a highly competitive and globalized environment. It can be said that the XXIst century is being marked by profound changes in manufacturing processes, based on new models of human and inter-institutional relationships with a focus on innovation. In a context of uncertainty, worsened by a major international economic crisis with conse-

\footnotetext{
* Corresponding author.

E-mail addresses: acastro@cnptia.embrapa.br, alxcas@gmail.com (A. de Castro).
}

quences that have yet to be measured, there is a need for rapid and strategic adaptation of political, economic, and social organizations to ensure survival in an extremely vulnerable environment. What we are facing is a changing techno-economic paradigm requiring a new and integrated management approach. A relevant option that emerges in this scenario is knowledge management, because it enables the strategic use of information to build consensus and promote organizational learning, in turn creating new knowledge to facilitate decision-making (Choo, 1998).

A concrete way for companies to increase their competitiveness is to understand that all their knowledge, either embedded in their products and organizational processes or stored in the minds of their people, can be managed, because it is the result of a social interaction dynamic. Those companies that dominate in the field of knowledge management show greater capacity for technological innovation, which results from the creation of processes, products, new skills and technical expertise, infrastructures, and technologies that facilitate the creation, transformation, and dissemination of knowledge. The great contemporary business challenge is to create a conceptual and methodological framework that enables a company to manage its knowledge in a web of social interaction.

This paper is aimed at analyzing, from a theoretical and exploratory point of view, the way in which the conceptual ideas embodied in the current approaches to knowledge management 
and communication inter-relate. An approach encompassing these two concepts is essential, because, at the heart of the problem of defining and implementing models of knowledge management, communication has the role of making information flow in the network of relationships and social interactions.

We can say that, in a knowledge-based society in which the communication occurs in complex environments marked by uncertainty (Giddens, 1991), companies lack an effective process of communication.

For this analysis, the Brazilian Agricultural Research Corporation (Empresa Brasileira de Pesquisa Agropecuária-Embrapa) was used as a reference. It is a public company, linked to the Ministry of Agriculture, Livestock and Supply of the federal government of Brazil.

Our work here is divided into two sections, in addition to this introduction and our closing remarks. In the first of these, the general context of Embrapa is presented, highlighting its strategic need for knowledge management and the role of communication in this process. In the second, a conceptual discussion is developed about the interface between the knowledge management and communication approaches, to underscore the aspects that may contribute to the definition of a knowledge management model. In the closing remarks section, we offer some further thoughts and the outlook for information management in agricultural research companies.

\section{Management system research at Embrapa}

Today, the mission of Embrapa, founded in 1973, is to seek solutions to development and innovation issues in tropical agriculture. Technology transfer is also part of the innovation process, as it provides the opportunity for the technologies generated to be implemented (Embrapa, 2008). Over its 37 years, Embrapa has been guided by building the scientific knowledge that has revolutionized tropical agriculture. Its success is due in large part to understanding that both the marketplace and the society are sources of information that can help prioritize future actions.

In its Vth Master Plan for the period 2008-2011-2023 (Embrapa, 2008), new institutional policies for the planning of research and strategic management of the company were drawn up, based on new scenarios and future challenges that are currently envisaged. As a consequence, it has established a research model, the Embrapa Management System (SEG, its acronym in Portuguese), the orientation of which is the development of a process of technological innovation and the strengthening of sustainable development.

\subsection{Embrapa Management System (SEG)}

In addition to recognizing Embrapa's need to embrace the new economic, social, ecological, and environmental values, the SEG brings together the common interests of various social agents through converging of concatenated actions. These actions are executed through a macroprogram designed to meet the demands of the society and which comprises the strategic guidelines, specific objectives, resources, and forms of communication for innovation.

From the standpoint of an integrated, inter-disciplinary, and preferably multi-institutional network, the projects developed within the framework of the macroprogram combine various features, especially intangible ones, in order to produce new knowledge and technologies. Thus, the research model set out in the SEG focuses on the social interaction that occurs within research projects, in the learning processes that are developed, and in the generation of knowledge based on collaboration and cooperation among peers.

In establishing the SEG, the company confirmed its belief that knowledge management is a necessary management policy, because it is concerned with the expansion of the capacity of both individuals and research projects. This shows that Embrapa's interest is not limited to managing the knowledge produced, but also to identifying how it is produced through research projects. In this context, communication at Embrapa has the strategic role of supporting the actions of competitive intelligence, which contributes to ensuring institutional sustainability. Among the strategic guidelines established to promote RD\&I, the construction of tools and strategies focused on the use of new technologies and the organization of the knowledge management process are of prime importance.

In addition, the company proposes to adopt an innovative strategy for the transfer of knowledge and technology in order to create, maintain, and expand formal and informal spaces for dialog between the institution's internal public and its external public. This strategy will strengthen organizational intelligence and establish a policy of participatory management.

This view, related to knowledge management and the role of the communication process, is dynamic in nature and its premise is collaborative, on the one hand ensuring greater adherence to its mission and institutional objectives, and, on the other, the possibility of implementing policies and management practices that promote/increase the generation and dissemination of new knowledge.

Fig. 1 shows the general structure of the SEG, in which there are three levels of performance. At the strategic level, foresight actions aimed at seeking guidelines for RD\&I, technology transfer, communication, and institutional development are organized and implemented.

At this level, the Embrapa Master Plan and the Institutional Research Agenda are produced, which list societal demands in broad strokes and set strategic directions, as well as identifying the resources and forms of communication that will enable the company to fulfill those needs. At the tactical level, the company's project portfolio is managed. The portfolio consists of six macroprograms, which must be implemented by sharing resources, both tangible and intangible, provided through its internal infrastructure and its partners. At the operational level, projects are carried out and RD\&I processes are incorporated into the six macroprograms at the tactical level, to align them with the company's strategies and research units.

\section{Knowledge management and communication: interfaces and dialogs}

The literature has been steadily strengthening the interface between the process of knowledge management and business communication, the latter understood as one of the critical elements in the success of the former (Martensson, 2000; Sharp, 2003). Historically, forms of communication have always been associated with the socioeconomic model of progress and development in a society. The process of communication in companies has for a long time been regarded as having a merely instrumental and functional character, but is now considered to be an important and sophisticated practice that contributes to the achievement of organizational objectives. The need for greater transparency in the relationship with stakeholders means that companies have to plan, build, and strategically manage communication, maintaining a close relationship with all its audiences (Tapscott \& Ticoll, 2003).

Because of the dynamic character of communication in the digital age, companies try to enter into intense and permanent communication process, and this effort should be guided by the concept of the social network. This concept adds a new communication pattern to the relationship among the members of a group, but it also makes that relationship more complex and dynamic, and prevents it from following a predetermined track. 


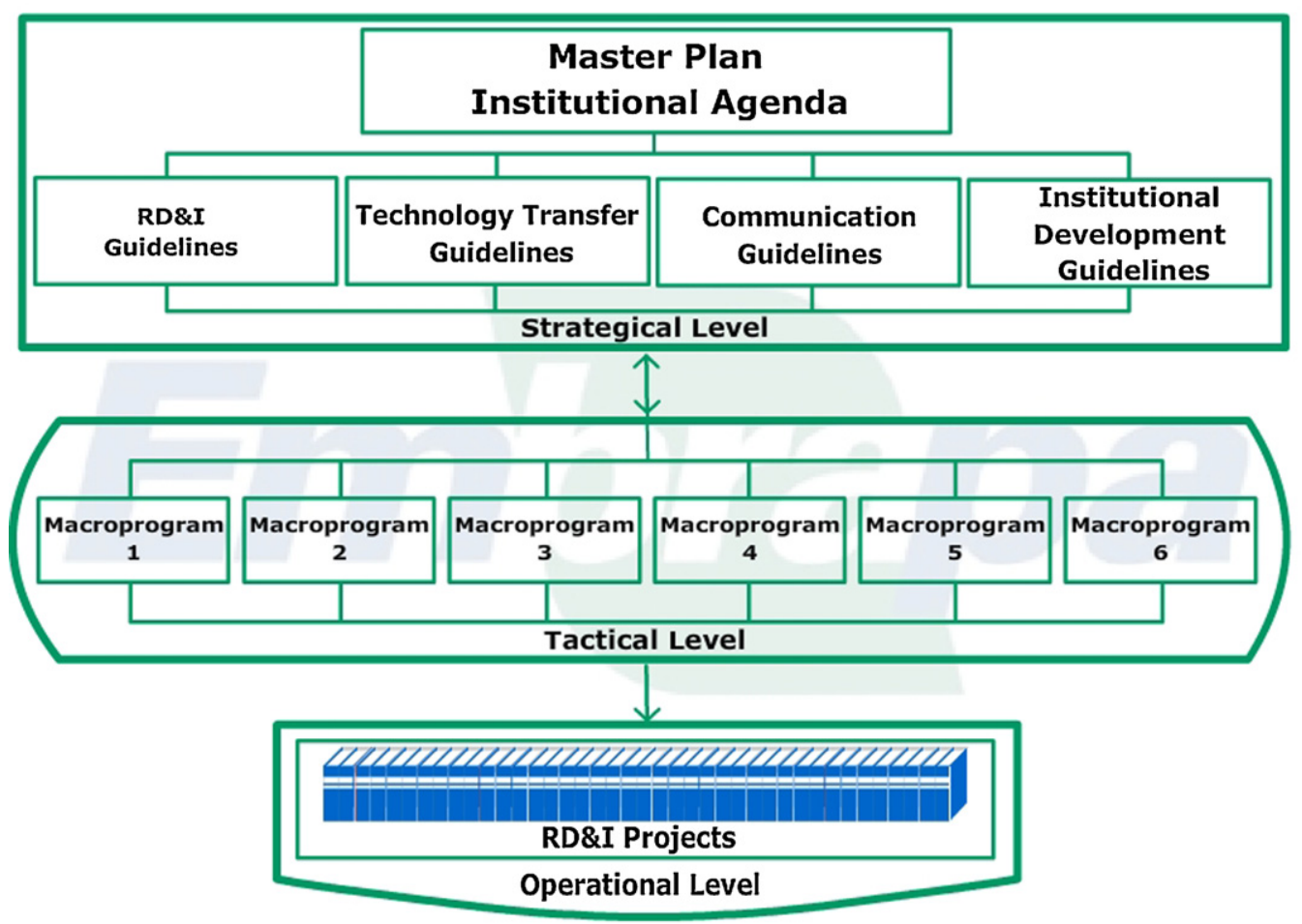

Fig. 1. General vision of the Embrapa Management System (SEG). [Figure adapted from Embrapa (2004)].

In social networks, the flow of communication is affected by the possibility of individuals interacting with their peers and of producing their own personal networks.

In this sense, communication plays a crucial role in the formation of a collective intelligence which, on one hand, helps us deal with the excess of information, and, on the other, offers us a new vision of the culture in which we find ourselves (Lèvy, 2002).

\subsection{Business challenges and communication}

In the face of these new business challenges, communication must increasingly be a horizontal, interactive, collaborative, and dynamic process, and it should also contribute to leveraging learning and the creation of knowledge.

We must understand knowledge management from the perspective of active communication, which is seen as having both procedural and interactive characteristics (Kuhlen, 2003). Managing knowledge cannot be solely the result of a special procedure of identification, retrieval, use, and distribution, but must also stem from a continuous process of management of the social interactions that occur among individuals in organizations. In other words, the management of knowledge is also the management of a process of intense communication permeated by the concept of the social network.

At Embrapa, the role of communication in the context of knowledge management is to facilitate learning developed within social interactions. To achieve this, channels of communication are set up with a view to overcoming the physical boundaries to improving access to information and to establish an opportunity for cooperation among individuals participating in RD\&I networks.

In our organization, the importance of using of technologybased communication channels - such as chats, blogs, and digital repositories - is well recognized. These channels also build and integrate relationships among people, creating greater social cohesion. In this era of communication and IT, companies should feel free to evolve into a state of active interaction (Mcluhan \& Fiore,
1967; Littlejohn, 2002). The electronic media are effective ways to achieve this, both as instruments that promote the formation of interactive, collaborative, and horizontal social networks, and as instruments to leverage the creation and dissemination of knowledge. In Section 3.2, we present an example of how this approach has been implemented by Embrapa.

Although there is broad acceptance that knowledge is a strategic factor, and managing it is an important issue - because it enables the creation of competitive advantage for businesses the results of research on the application of methods and techniques of knowledge management are not often implemented in the research groups of RD\&I companies (Smith \& Farquhar, 2000). This has to do with the particular characteristics and specificities of these institutions that cannot be ignored, especially with respect to the establishment of a model of knowledge management. Market requirements, social demands, the interdependence of phenomena, and the magnitude of the challenges of agricultural research drive companies to identify new institutional arrangements. At Embrapa, the formation of research networks has been the alternative chosen, because, besides promoting integrated solutions, it improves the companys inter-disciplinary and transverse vision of the problems it faces. The scope of these networks enables researchers to maximize their chances of recognizing that their research problems are complex and interconnected. Moreover, networks are conducive to the building of bridges that permit navigation between different areas of knowledge and the establishment of links that cover the multitude of relationships inherent in the research problem itself (Gallo, 2000).

Research networks face numerous challenges in the quest for results (Smith \& Farquhar, 2000). Among those that should be considered because of their impact on the management of knowledge are the following: excess of information produced by the network; the speed with which members of the network replace concepts, tools, and methods; the requirement for a high level of expertise on the part of researchers; and activity overload experienced by network coordinators, administrators, and those performing the 


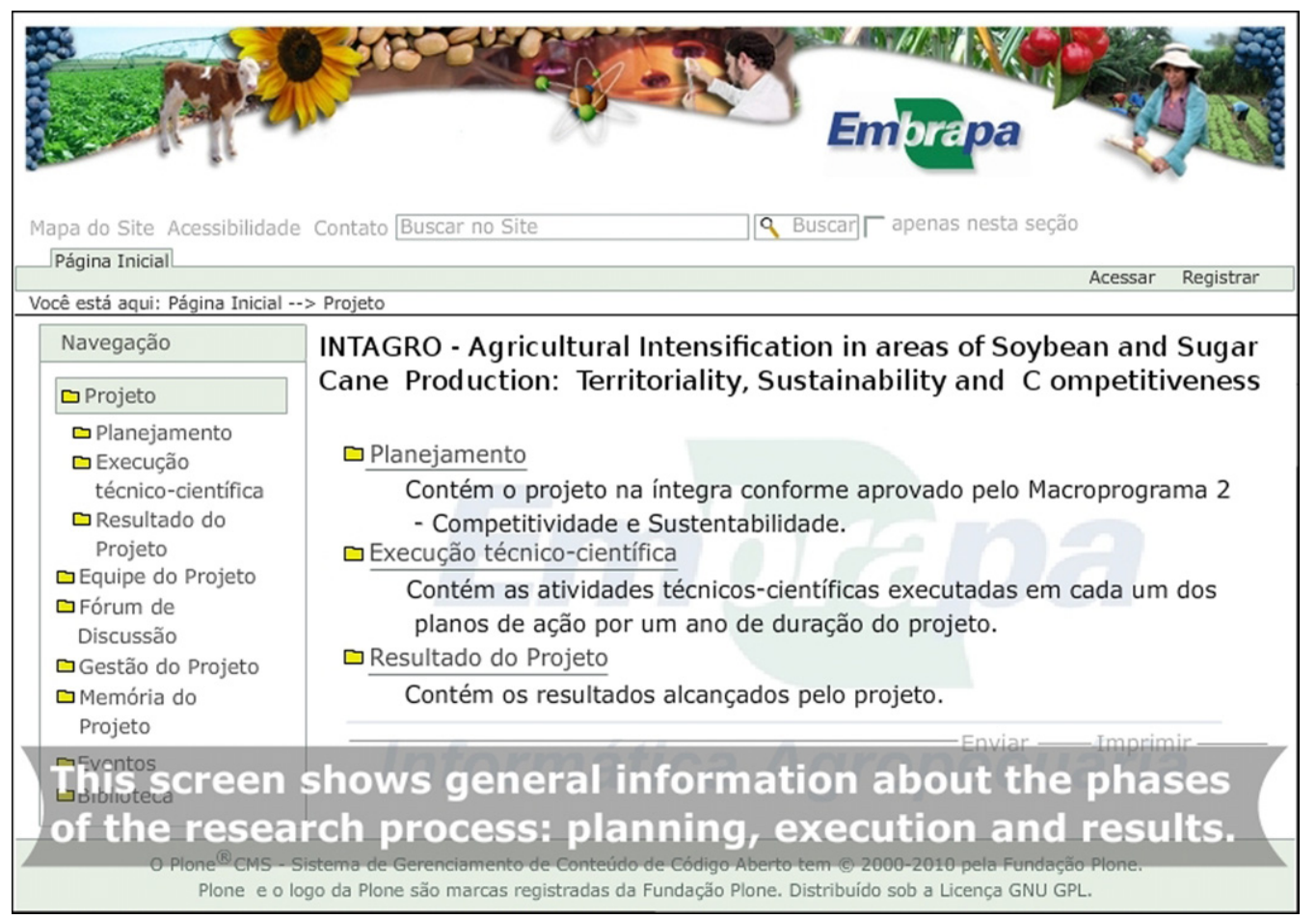

Fig. 2. Screen to display the general information about the research process.

activities. The SEG was set up to minimize these issues and to optimize the dynamics of knowledge production. As shown in Fig. 1, the RD\&I projects at Embrapa at the operational level are articulated in research social networks to integrate the project portfolio of six macroprograms (tactical level) that feed into the cooperative guidelines (strategic level). At Embrapa, knowledge management takes into consideration the circumstances in which knowledge is produced, as well as the environmental, cultural, and communi- cation factors that support relationships and social interaction. An example of this practice is provided in Section 3.2.

As the experience at Embrapa shows, knowledge management can be incorporated into the research social networks. In this case, the substratum that customizes these networks is the research project itself. Individuals from the various knowledge areas are involved in this process, and they take on the responsibility of proposing solutions to each particular problem, according to a sys-

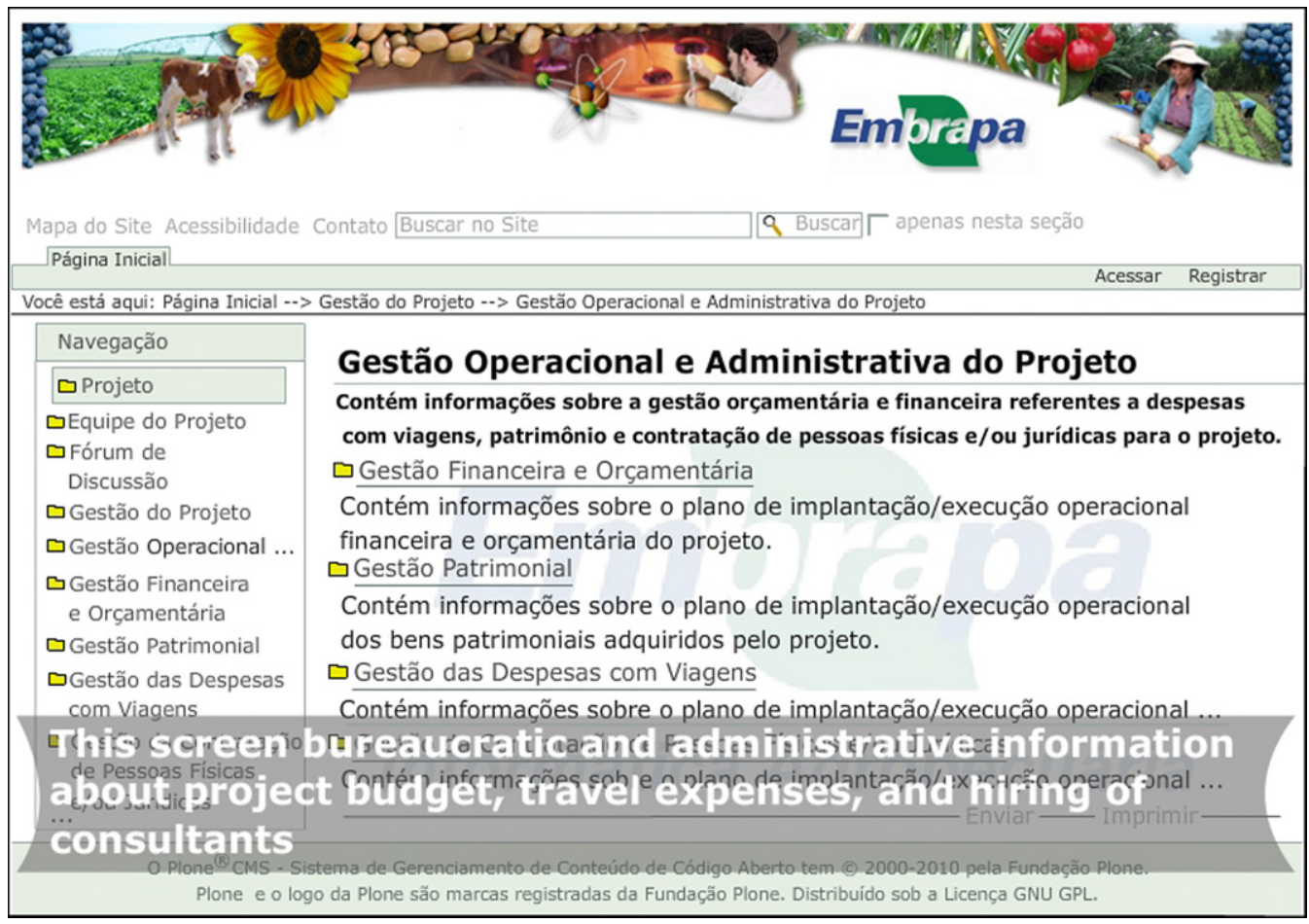

Fig. 3. Screen to display the operational and administrative management of the research project. 


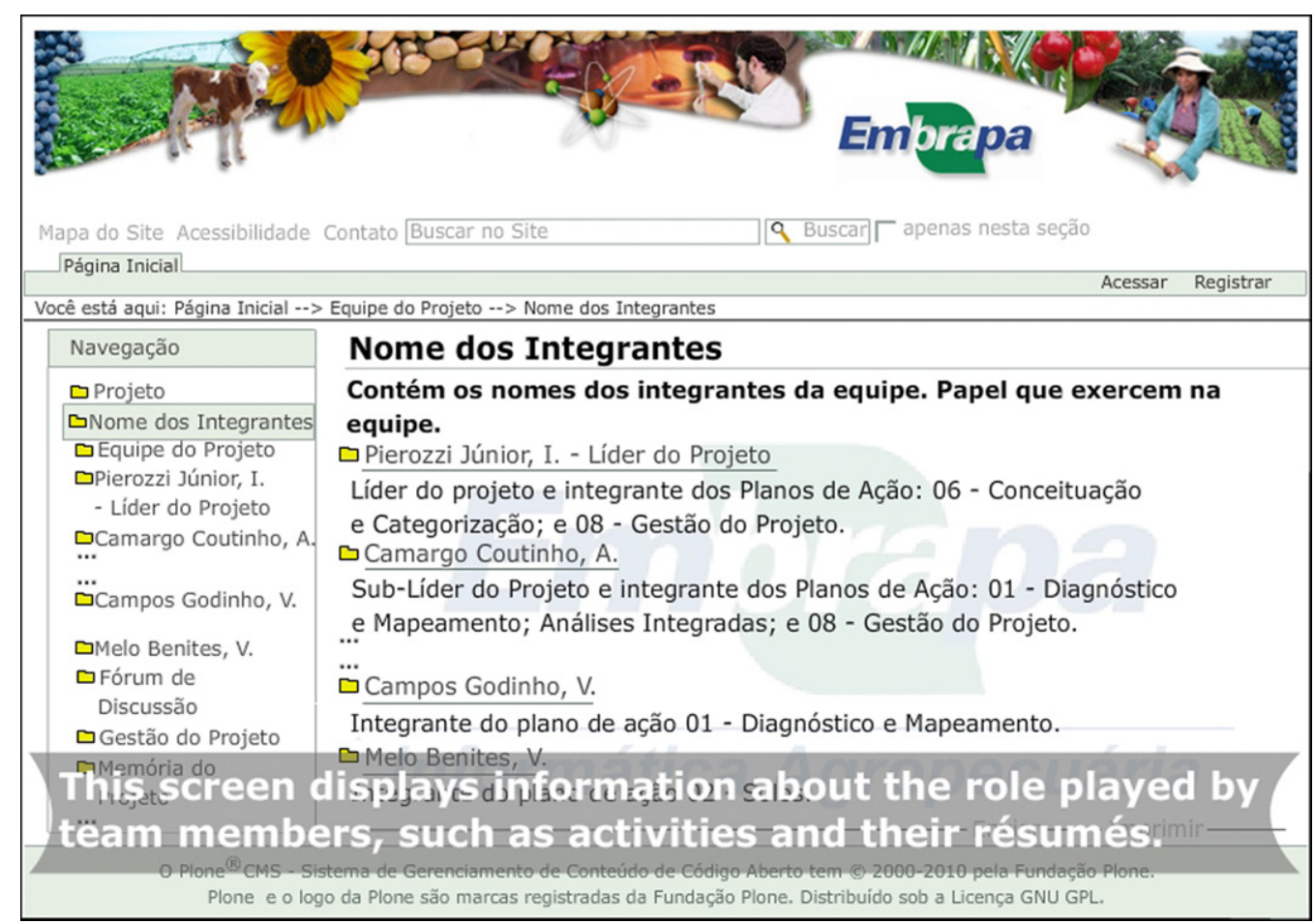

Fig. 4. Screen to display the expertises of the research project team.

temic and integrated vision. It is in this, the research project space, that the company establishes the conceptual basis for managing knowledge.

The close relationship between knowledge management and the learning process as reported in the literature (Jones, 2001) further strengthens the idea that the knowledge to be managed - in the case of Embrapa and other research institutions - should be produced as a direct result of the interactions that occur among research networks. From this perspective, the management of knowledge can drive the creation of knowledge, because knowledge management and knowledge creation are so closely aligned in the research context through communication, allowing greater adherence to the reality experienced by the individuals (Smith \& Farquhar, 2000).

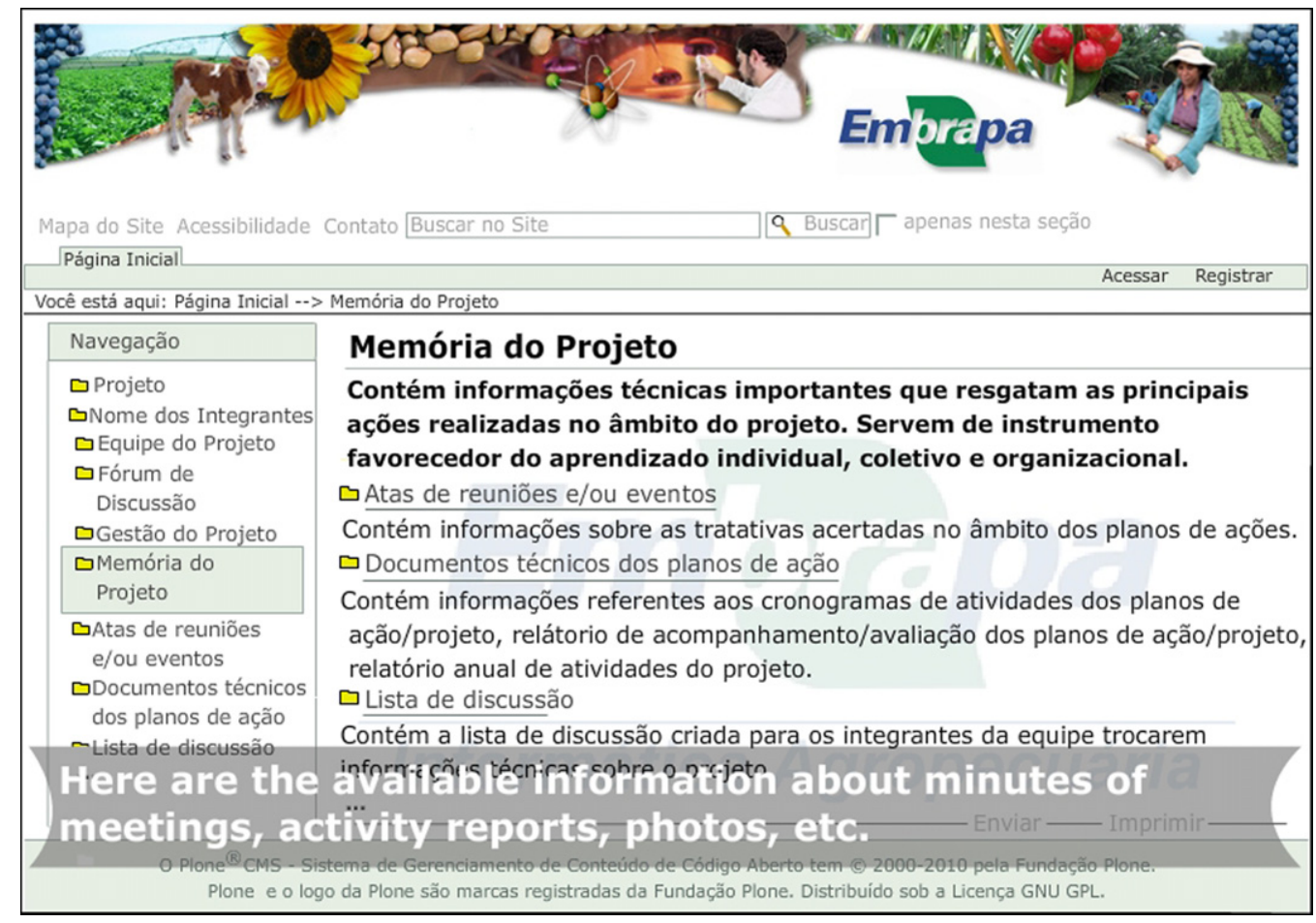

Fig. 5. Screen to display the memory of the research project. 


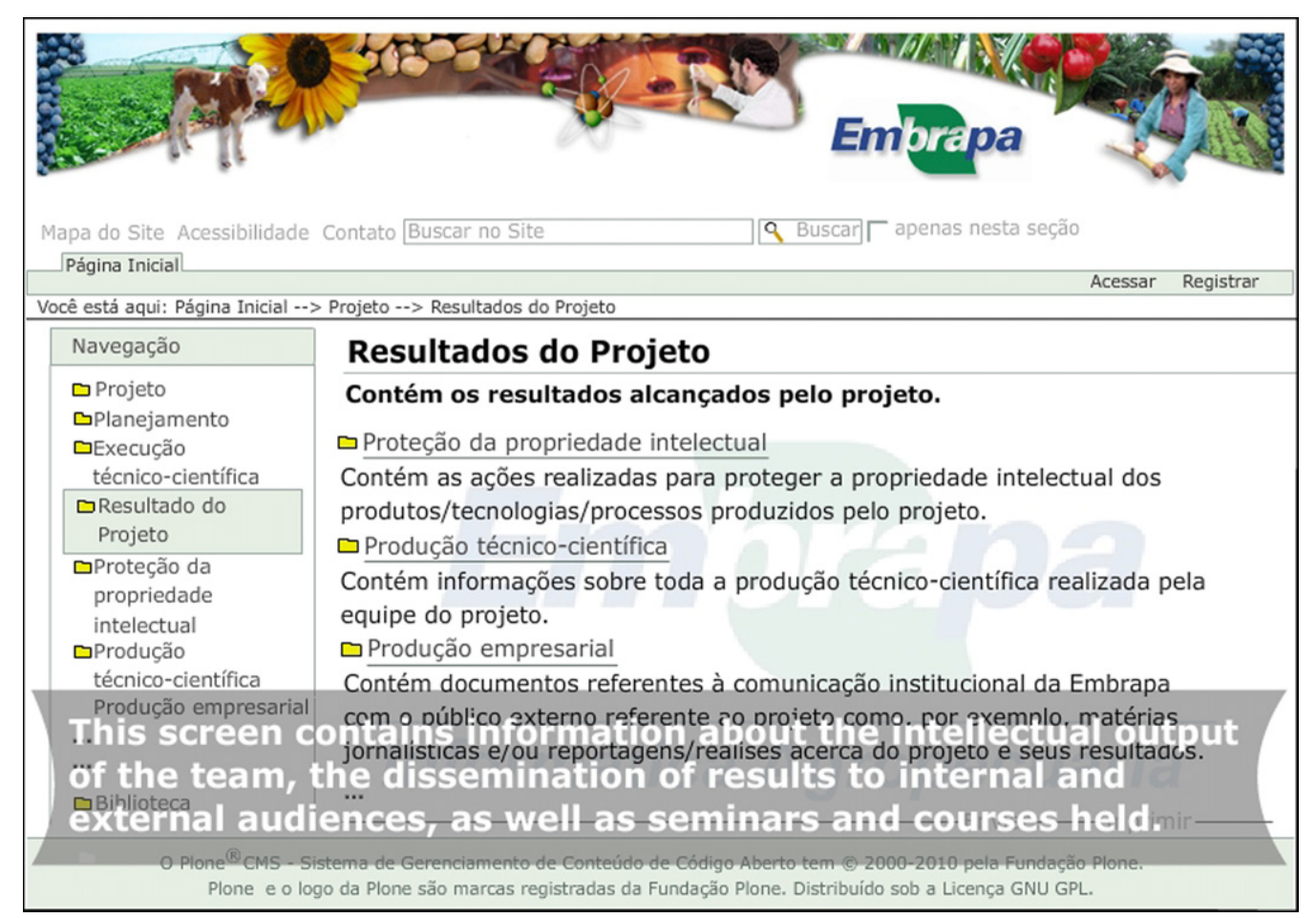

Fig. 6. Screen to display the results achieved by research project.

\subsection{INTAGRO: a project for interactive governance}

At Embrapa, this vision has been incorporated into the project entitled "Agricultural Intensification in the Areas of Soybean and Sugar Cane Production: Territoriality, Sustainability, and Competitiveness" (INTAGRO, the acronym in Portuguese). This project, led by Embrapa Agriculture Informatics, with the involvement of Embrapa's other five research centers and four external RD\&I Institutions, was started in 2009 and is scheduled for completion in 2012. The objective of the project, designed with the research social network in mind, is to collect, analyze, categorize, and disseminate information about the relationships between agricultural intensification processes and the dynamics of the use and occupation of land, in clusters of significant production of soybeans and sugar cane in Brazil, focusing on their relationships with agronomic, environmental, and socioeconomic variables.

The guiding principle behind INTAGRO is to study mechanisms based on the concept of governance as an interactive action, in which all the agents involved have the knowledge, the resources, and the capacity to solve problems unilaterally (Stoker, 2000). This management perspective emphasizes the practical application of the concepts that motivate the SEG, and helps to promote discussion and interaction among those involved, allowing them to produce alternatives to structuring, organizing, and disseminating information and knowledge which are more compatible with the objectives of the project. Accordingly, the projects management was structured to enable the entire team to implement actions that optimize the management of a knowledge that has been collectively built.

To meet this challenge, a virtual environment was developed in which research actions can be conducted, organized, structured, developed, and disseminated. This tool is an intranet site (https://intranet.embrapa.br) developed on a Web platform, the knowledge management-related content of which is organized based on the logic of the research process, i.e. in three stages: planning, execution, and results (see Fig. 2). In addition to this information, there is specific content on the site for the opera- tional management of the project, which includes information of an administrative and bureaucratic nature that is important because it generates procedural knowledge (see Fig. 3).

The site also provides information on the team members, including their experience and expertise (see Fig. 4). This allows the leader of the RD\&I social network to integrate the various fields of knowledge of the team members into the scope and objectives of the research, which enhances the value of the projects expected results. It also allows new knowledge to be acquired by members of the research social network.

The site provides technical-scientific information produced by the project as well, and the inputs required for its implementation, such as a digital library of documents identified by knowledge area, author(s), and title, and by type of documentation: project memoranda, including minutes of meetings and activity reports; a photo gallery; and a discussion forum (see Fig. 5).

Finally, the site makes information available to enable comparison between the expected results and the results achieved, with a focus on the following: protection of intellectual property of the products, technologies, and processes that identify the product type; features and specifications, functionality, and intended market; the take-up of the product/technology/process in the marketplace; the actions taken by project managers to protect intellectual property; technical-scientific production; and the events promoted by the project team for their own network or for other audiences (see Fig. 6).

\section{Conclusion}

The implementation of knowledge management initiatives brings with it the need to deal with issues of organizational culture, which can be considered from the apriorist or the constructionist point of view. The first is being abandoned because it no longer represents the experience of organizations dealing with the cultural complexity of a globalized world. The second is seen as dynamic, part of a set of symbolic and practical relations that helps to build the cultural identity of the organization and the individuals 
belonging to it. From the cultural constructionists perspective, the alignment of knowledge management and communication is confirmation of the need to manage knowledge in RD\&I institutions from the start of the research project.

In this paper, we show that the practice of knowledge management can be initiated within the research process itself. This means that it can be inserted into the process from the moment the research problem is first conceived to its final outcome. This new approach, which has been implemented by the INTAGRO project team, has helped to consolidate at Embrapa this new way of thinking about knowledge in the realm of RD\&I activities.

The experience of the INTAGRO project staff suggests that this approach could also provide a concrete opportunity for similar companies to capture the knowledge and skills of its researchers, in order to produce improved solutions to a number of pressing issues in contemporary agricultural research.

\section{References}

Choo, C. W. (1998). The knowing organization: How organizations use information to construct meaning, create knowledge and make decisions. New York: Oxford Press.

Embrapa. Boletim de Comunicações Administrativas. (2004). Fundamentos, Estrutura e Funcionamento do Sistema Embrapa de Gestão - SEG. Brasília, DF: Embrapa 30(38), 14-25.

Embrapa. Secretaria de Gestão e Estratégia. (2008). V Plano Diretor da Embrapa: 2008-2011-2023. Brasília, DF: Embrapa.

Gallo, S. (2000). Transversalidade e educação: Pensando uma educação nãodisciplinar. In N. Alves, \& R. L. Garcia (Eds.), O sentido da escola (4th ed., pp. 17-41). Rio de Janeiro: DP\&A.

Giddens, A. (1991). Modernity and self-identity: Self and society in late modern age. Cambridge, England: Polity Press.

Jones, P. M. (2001). Collaborative knowledge management, social networks, and organizational learning. In Proceeding of HCI International 2001: Ninth International Conference on Human-Computer Interaction. Available at: http://humanfactors.arc.nasa.gov/publications/. Accessed in May 2, 2010
Kuhlen, R. (2003). Change of paradigm in knowledge management: Framework for the collaborative production and exchange of knowledge. In Word Library and Information Congress: 69th IFLA General Conference and Council Berlin, 1-9 August 2003.

Lèvy, P. (2002). Cyberdemocratie. Paris: Odile Jacob.

Littlejohn, S. W. (2002). Theories of Human Comunication (7th ed.). Belmont, CA: Wadsworth.

Martensson, M. (2000). Critical review of knowledge management as a management tool. Journal of Knowledge Management, 4(3), 204-216.

Mcluhan, M., \& Fiore, Q. (1967). The medium is the massage. New York: Bantam.

Sharp, D. (2003). Knowledge management today: Challenges and opportunities. Information Processing and Management, 20(2), 32-37.

Smith, R. G., \& Farquhar, A. (2000). The road ahead for knowledge management: An perspective. Al Magazine, 21(Winter (4)), 17-40.

Stoker, G. (2000). Urban political science and the challenge of urban governance. In J. Pierre (Ed.), Debating governance: Authority, steering and democracy (pp. 91-109). New York: Oxford University Press.

Tapscott, D., \& Ticoll, D. (2003). The naked corporation: How the age of transparency will revolutionize bussiness. New York: Free Press.

Tércia Zavaglia Torres is a research analyst of the Brazilian Agricultural Research Corporation with experience in knowledge management, human and organizational development, and individual and organizational learning. She is professor of Knowledge management at the Universidade Paulista and also at the Faculdade de Paulínia, both in São Paulo State.

Ivo Pierozzi Junior is a researcher at the Brazilian Agricultural Research Corporation. His primary area of research is knowledge management and project administration. He has worked in conceptual maps, ontologies and information systems to business management.

Nadir R. Pereira is a journalist at the Brazilian Agricultural Research Corporation. She is specialized in cientific journalism and responsible for reporting and for business communication of Embrapa Agriculture Informatics.

Alexandre de Castro is a researcher at the Brazilian Agricultural Research Corporation with experience in computational modeling and simulation. Currently, he has worked in modeling of collective and cooperative behaviors in biological and organizational systems. His research about computational modeling and simulation has appeared in Computer Modeling in Engineering \& Sciences, Simulation Modelling Practice and Theory, Physica A: Statistical Mechanics and its Applications, Lecture Notes in Computer Science, and The European Physical Journal. 